\title{
Strategic trade policy with interlocking cross-ownership
}

\author{
Luciano Fanti ${ }^{1} \cdot$ Domenico Buccella ${ }^{2}$
}

Received: 30 October 2018/ Accepted: 2 May 2021 / Published online: 23 May 2021

(C) The Author(s) 2021

\begin{abstract}
By analysing interlocking cross-ownership, this work reconsiders the inefficiency of activist governments that set subsidies for their exporters (Brander and Spencer, J Int Econ 18:83-100). Making use of a third-market Cournot duopoly model, we show that the implementation of strategic trade policy in the form of a tax (subsidy) when goods are differentiated (complements) is Pareto-superior to free trade within precise ranges of firms' cross-ownership, richly depending on the degree of product competition. These results challenge the conventional ones in which public intervention (1) is always the provision of a subsidy and (2) always leads to a Paretoinferior (resp. Pareto-superior) equilibrium when products are substitutes (resp. complements).
\end{abstract}

Keywords Export subsidy · Prisoner's dilemma · Interlocking cross-ownership · Cournot duopoly

JEL Classification F13 - L13

\section{Introduction}

The subsidy policy for firms is a cornerstone of the public intervention in exporting sectors, in particular those that governments consider to be of strategic importance. The relevance of the debate over this subject is ongoing regarding the latest

Domenico Buccella

buccella@kozminski.edu.pl

Luciano Fanti

lfanti@ec.unipi.it

1 Department of Economics and Management, University of Pisa, Via Cosimo Ridolfi, 10, I, 56124 Pisa, PI, Italy

2 Department of Economics, Kozminski University, Jagiellońska Street, 57/59, 03301 Warsaw, Poland 
decisions of the Dispute Settlement case between the United States and the European Union within the World Trade Organization on September 22, 2016 and on October 13, 2020; the decision was made concerning the Subsidies and Countervailing Measures in the aircraft industry (WTO, 2016; The Seattle Times, 2016; The Economist, 2020). ${ }^{1}$

This feature of contemporary economics is timely and relevant for investigation. A renewed debate on whether free trade or trade policies are suitable to improve the national welfares of countries engaged in international trade is high on the current political agendas.

Consider, for example, the case of the United States. Recently, the Obama administration supported bilateral free-trade agreements with countries including Colombia, Panama, and South Korea. Moreover, it has been conducting and promoting negotiations on two large regional multi-lateral agreements, the Asiacentered Trans-Pacific Partnership and the Transatlantic Trade and Investment Partnership with the European Union. The subsequent Trump administration has chosen to reassess those avancements, instead considering the opportunity to introduce trade policies (see Scott and Glass, 2016; Scott, 2016).

The strong suggestion of the early Brander and Spencer's approach (Brander, 1981; Spencer and Brander, 1983; Brander and Spencer, 1985, 1988) is that, in an export-rivalry context, the implementation of a trade policy is optimal for the national social welfare. Therefore, those contributions have provided theoretical support for a resurrection of neo-mercantilist/neo-protectionist ideas, even though limited to the assumptions of quantity competition, duopoly and short period context (no entry). ${ }^{2}$

However, even accepted the argument that unilateral trade policies are welfareenhancing for the activist government, the possibility of retaliation not only weakens but also totally reverses the outcome, once a correct "game-theoretic approach" is considered.

In fact, the well-known prisoner's dilemma game structure in which both governments decide whether to subsidise implies the paradox that while firms and worldwide consumers benefit from the trade policies, national social welfares are harmed. The subsidy policy is undeniably effective to gain an advantage when the rival country does not intervene. However, if the other country also uses that policy, the outcome is that both exporting countries would be better off if none of them had used it.

\footnotetext{
${ }^{1}$ On September 22, 2016, the World Trade Organization (WTO) condemned the European Union (EU) for the state aid to Airbus because it has considered illegal the subsidies granted by various EU member countries to the European aerospace giant. More generally, the compliance panel of the WTO has condemned the EU, Germany, France, and Spain for having given $\$ 22$ billion in 10 years to Airbus, recognizing that those aids have created a "real and substantial damage" to its rival Boeing. The subsidies relate to the A300 project, A310, A320, A330 / A340, A330-200, A340-500 / 600, and A380. Airbus counterattacked presenting its own claim that Boeing had taken advantage from $\$ 24$ billion in favorable tax breaks and R\&D support from NASA and the Pentagon. On October 13, 2020, the WTO ruled that the EU can levy tariffs on $\$ 4$ billion-worth of United States goods annually.

2 The literature originated from the Brander and Spencer's works-i.e. the "strategic trade policy" approach — and the subsequent intense debate is surveyed, e.g., by Krugman (1986), Grossman et al. (1986), Dixit (1987), Helpman and Krugman (1989) and Brander (1995).
} 
As Spencer (1986, 70-71) remarks, a crucial point is the recognition of the types and characteristics of industries to be targeted with the subsidy policy instrument because the "identification of these characteristics is a preliminary step toward translating theory into practical policy proposals".

Recently, Fanti and Buccella (2016a) have extended the Brander and Spencer's approach, developing a model in which strategic trade policy occurs between economies with unionised labour markets and showing that the scope of bargaining between firms and unions depend on how governments compete between them in export/tax subsidies.

On the other hand, the current financial globalisation suggests that it would be fruitfully to embed this phenomenon into the Brander and Spencer's approach. Indeed, a stylised fact of increasing importance in international oligopolistic industries is the widespread presence of interlocking cross-shareholdings.

Companies in cross-ownership structures are linked by horizontal crossshareholdings that reinforce and strenghten the power of central controllers. Thus, in cross-holding structures the voting rights used to control a group remain distributed over the entire group (Bebchuk et al., 2000).

Most studies have considered a simple ownership structure with only one shareholder having participation in both firms. ${ }^{3}$ In the real world, there are more complex cross-shareholdings links: for instance, "cross participations" with each firm possessing a small amount of shares of the other (i.e. two-sided crossownership, e.g. Cai and Karasawa-Ohtashiro, 2015), or "multiple participation" with more complex direct as well as indirect links (e.g. Gilo and Spiegel, 2003; Dietzenbacher and Temurshoev, 2008).

In particular, Cai and Karasawa-Ohtashiro (2015) investigate the impact of international cross-ownership of firms on the strategic privatization of a partially privatized public firm. In a third-country model in which a domestic public firm competes with a foreign privately owned firm, the authors show that, under Cournot competition with a linear demand function, the domestic ownership of foreign firms can hamper privatization. On the other hand, the foreign ownership of the domestic public firm can promote the privatization policy. Moreover, under certain conditions, the domestic ownership of foreign private firm can make both complete privatization and complete nationalization sub-optimal. If competition takes place á la Bertrand, complete nationalization becomes always the optimal policy. However, those authors abstract from the analysis of strategic trade policy.

The present paper does not consider the subject of strategic privatization and focuses on the strategic trade policy in an export-rivalry model with mutual (twosided) minority cross-participation at the ownership level. ${ }^{4}$

\footnotetext{
3 Only to mention a few, among many others, Farrell and Shapiro (1990), Macho-Stadler and Verdier (1991), Reitman (1994), Dickescheid (2001), Barcena-Ruiz and Olaizola (2007), Barcena-Ruiz and Campo (2012) and Fanti (2013, 2014) analysed various effects of cross-ownership mainly in the simplified frame of one-sided cross-ownership, but none of them have dealt with the issue of strategic trade policy in an export-rivalry context.

4 As a referee has correctly pointed out, information on cross-ownership can be difficult to track and observe, particularly for minority holdings. Nonetheless, Thomson-Reuters provides an ownership database called the Thomson-Reuters Global Ownership database in which institutional ownership data
} 
Empirically, foreign equity ownership has demonstrated to lessen considerably, and sometimes invalidate, the accepted results of the strategic trade policy. For example, Dick (1993) shows that the levels of United States (minority) crossownership decrease the average optimal export subsidy by $47 \%$ compared with those Brander and Spencer (1985) estimate.

Because the relationship between strategic trade policies and two-sided crossownership, to the best of our knowledge, has not been fully explored, this paper questions if the common wisdom that the public interventions lead to a Paretoinferior equilibrium (i.e. the game between governments is a prisoner's dilemma) still holds under the presence of interlocking cross-ownership between rival exporting firms.

The paper develops a two-stage game. In the first stage, governments of the exporting countries decide simultaneously and independently on the optimal subsidy to maximize their own social welfare. In the second stage, by playing a noncooperative Cournot oligopolistic game, firms' owners choose their output and employment levels, taking subsidies as determined in the prior stage. We proceed, as usual, by backward induction to determine sub-game perfect Nash Equilibria (SPNE).

The essential feature of the existence of a two-sided cross-ownership in the output market (abstracting from the possible trade policy) is that both firms behave in a "more collusive" way because each firm internalizes the fact that both firms compete in the product market. ${ }^{5}$ The collusive behaviour of firms in the product market affects the government's behaviour, in the sense that each government reduces the subsidy (or increases the tax) when the degree of "collusion" increases. In turn, this government's behaviour tends to transform the effects of "more collusion" on profits from positive to negative.

In the absence of cross-ownership, trade policy (1) is always under the form of a subsidy and (2) always leads to a Pareto-inferior (resp. efficient Pareto-superior) equilibrium when products are substitutes (resp. complements). In other words, under product substitutability, the game played by governments presents the structure of the prisoner's dilemma.

The main result of the paper is that the presence of reciprocal cross-ownership eliminates the prisoner's dilemma structure under appropriate degrees of product competition, and thus, in contrast to the traditional wisdom, public intervention is optimal in equilibrium.

This result also relates to the above-mentioned debate about the weakness of the public intervention suggestion, showing that in the presence of mutual crossownership and differentiated products, a corresponding retaliatory action following a unilateral trade policy could lead to a welfare-superior Nash policy equilibrium with regard to the free trade for both countries.

\footnotetext{
Footnote 4 continued

starting in 1999 are reported, despite some technical problems (see Wharton Research Data service, 2019).

5 At the limit, when the mutual cross-ownership share approaches $50 \%$, both firms equally share monopolistic profits.
} 
This unconventional welfare result occurs because mutual cross-ownerships always increase profits (and thus social welfare) under free trade; however, under trade policy, on the one hand, cross-ownerships always reduce profits, but on the other hand, they reduce the subsidy spending or increases the tax revenue to such an extent that the fiscal gain outweighs the profit loss. As a consequence, social welfare may surpass that under free trade for a sizable range of intermediate values of the product differentiation degree.

Therefore, this finding that the national social welfare benefits from the trade policy in the presence of the anticompetitive practice of mutual interlocking crossownership offers an interesting policy implication: export firms with interlocked cross-ownership with the rival firm could be targeted for a subsidy/tax policy. Furthermore, one empirical implication is that trade policies should be more often observed when the targeted firms mutually cross participation.

The rest of the article is organised as follows. Section 2 describes in detail some real-world cases of bilateral cross-ownership. Section 3 presents the Cournot duopoly model under trade policy, along with the equilibrium analysis. In Sect. 4, the welfare analysis is presented, and the main results are shown and discussed. Section 5 discusses some extensions of the basic model and Sect. 6 concludes the paper.

\section{Bilateral cross-ownership: some examples}

The case of bilateral participations retaining minority stakes in rival firms is rather usual, and may have several explanations. ${ }^{6}$ Partial bilateral cross-ownership agreements can occur for several reasons:

1. To create incorporated joint ventures (i.e. a separate company which is legally incorporated in one the partner companies) in order to enter and expand in highly regulated markets. The most significant example is the low cost carriers in the ASEAN airlines industry, characterized by the fact that several states restrict foreign ownership in the airline sector to less than 50\%, requiring that national firms effectively take the control of the company (Lee and Yoon, 2020). Indeed, the typical business model developed is a parent airline group which holds a minority share while national owners hold a majority share. Examples of this business model are AirAsia, and Jetstar, Lion Air, Singapore Airlines, Spring Airlines, and VietJet, which have managed to set up their presence in foreign countries through such joint venture agreements;

2. In imperfectly competitive markets, acquiring passive shares in rivals, firms act less competitively (Flath, 1991; DCCA, 2017) and can create implicit collusion and increase market power (Amundsen and Bergman, 2002). For example, in Italy, ownership links between Italian-listed companies belonging to groups which both participate in others listed groups and participated in other listed groups in 1990 involved large companies representing a market value with a total stock market capitalization percentage of about $4.3 \%$ and involved companies' capitalization of

\footnotetext{
${ }^{6}$ This case has been recently analysed by Fanti (2016), but only in the context of a closed economy.
} 
about $10.9 \%$. This has had an impact on competition in the banking sector of crossownership between Italian banks (Trivieri, 2007; Bank of Italy, 2008);

3. They facilitate cooperation and mutual monitoring, as in the case of Japanese "keiretsu" (Berglof and Perotti, 1994), and can solve managerial myopia problems under the threat of hostile takeovers (Osano 2011). For example, only focusing on the Japanese automobile sector in 1993, Toyota (resp. Daihatsu) held shares in Daihatsu (resp. Toyota) of about 16.5\% (resp. 0.21\%), Toyota (resp. Hino) holds shares in Hino (resp. Toyota) of about $11.8 \%$ (resp. 0.2\%), Hino (resp. Daihatsu) holds shares in Daihatsu (resp. Hino) of about $0.15 \%$ (resp. 0.13\%), Nissan (resp. Fuji) holds shares in Fuji (resp. Nissan) of about 4.35\% (resp. 0.49\%), and Suzuki (resp. Isuzu) holds shares in Isuzu (resp. Suzuki) of about 1.7\% (resp. 1.32\%) (e.g. Alley, 1997);

4. Minority stakes in a rival's equity grant corporations to share the rivals' profits without obtaining their control (Nain and Wang, 2018). For example, in 2008, the German drugs and chemicals Bayer, via its unit Medrad, bought Possis Medical, a developer of pioneering cardiovascular devices, which previously, in 2006, purchased a $15 \%$ equity stake in Rafael Medical Technologies, a producer of embolic protection devices and vena cava filters (Reuters, 2008);

5. Strategic alliance to share technologies, develop joint products, and to pursue common strategic objectives in the common market. Two typical examples relate to the automobile industry ${ }^{7}$ and the steel industry: (1) In 1990, Renault acquired a $45 \%$ stake in Volvo Trucks, a 25\% stake in Volvo Car, and a $8.2 \%$ stake in Volvo A.B. (Volvo's holding company), while Volvo acquired $20 \%$ of Renault S.A. and $45 \%$ of Renault's truck-making operations (see "New Head is Selected For Renault," N.Y Times, May 25, 1992, p. 35, as reported by Gilo and Spiegel, 2003, p. 3). Subsequently, in 1999, Renault initially acquired a $36.8 \%$ stake in Nissan, while Nissan in turn took a $15 \%$ non-voting stake in Renault; and (2) Japanese Nippon Steel and Korean Pohang Iron, two of the worlds' largest steelmakers, held $0.5 \%$ ownership stakes in each other in the early ' 90 s, which then increased to $1 \%$ in the late ' 90 s and was planned to increase further to $3 \%$;

6. They allow firms to transfer innovation in industries with high technology know-how. Examples are the purchase of $15 \%$ of Japan Telecom by Vodafone, and

\footnotetext{
7 The automotive industry has been a typical sector targeted by trade policies, and the literature has devoted particular attention to that sector. Goldberg (1995) studies the implementation of Voluntary Export Restrictions and the exchange rate pass-through in the United States (U.S.) automotive market. With regard to the subsidy policy, a pioneering analysis of the strategic trade policy in the U.S. automotive sector has been carried out by Dixit (1988) and Krishna et al. (1989). In particular, Dixit (1988), assuming Cournot competition, analyses the strategic trade policy in the U.S. automotive sector implemented towards the Japanese competitors. His findings show "that the U.S. industry is more competitive than implied by a Cournot model but less competitive than a Bertrand model would imply" (quoted in Brander, 1995 p.1439). However, as Tremblay et al. (2013, p.129) remarks, it is natural to find in this sector both Cournot and Bertrand competition, depending on the strategy adopted by a specific brand, as in the case of Honda and Scion (a brand of Toyota Corporation) on the U.S. market: "Honda masses cars before bringing them to market, causing it to compete in output. Scion produces a custom car for each individual customer only after an order is placed, causing it to compete in price." The BertrandCournot competition can provide an interesting extension of the present model to be considered for further research. Today, the automotive sector still represents a target sector of industrial policies, as Nicolini et al. (2016) analyses with a focus on Europe.
} 
of $19.9 \%$ of Monsanto in InterGrain (an Australian rival) in 2010, both based on the explicit motivation of product innovation transfer (Papadopoulos et al., 2019);

7. Simply because of portfolio diversification: in the United States (only focusing on computer industry for 1994-95), cross-ownership relations are shown by those institutions that own about $77 \%$ of Intel and $71 \%$ of Compaq and at the same time have holdings in at least one of the other five computer industry companies listed (i.e. Apple, Compaq, IBM, Intel, Microsoft, Motorola) (Hansen and Lott, 1996).

At any rate, the cross-ownership choices, in general, are dictated by medium-long period strategies, for instance in the field of the competitive market structures, organizational structure of the business, or the companies' financial policy. Therefore, in the present paper, such choices are considered as exogenously given.

Moreover, we focus on the case of minority stakes because, as already underlined in point (1) above, governments can impose restrictions on the foreign ownership of national firms in some sectors of the economy. On a global perspective, the most restricted sectors are media, transport, electricity, and agriculture and forestry. For instance, despite the fact that high-income OECD countries have relatively few restrictions on foreign equity ownership, the transportation sector is rather more restricted.

In fact, in the airline sector, foreign ownership is restricted to a less than $50 \%$ stake in all high-income OECD countries covered by the World Bank's Investing Across Borders indicators. The Czech Republic, Ireland, and the Slovak Republic also have restrictions on foreign equity to the transportation sector (The World Bank, 2010). ${ }^{8}$ Therefore, the present model seems to be suitable to analyze the transport sector, characterized by the presence of both restriction on foreign participation and the widespread presence of different (direct and indirect) forms of subsidization, ranging from fuel subsidies to airport charge subsidies, and all along the value chain, from subsidies to manufacturers to airlines companies directly in the form of grants, equity infusions, loans, and loan guarantees (Gössling et al, 2017).

\section{The model with strategic trade policy}

Following the approach of the Brander-Spencer's (1985) model, we consider two exporting countries, each with a firm. Both firms (1 and (2) produce heterogeneous goods which are sold to a third country (i.e. an importing country) and compete between them regarding quantity (i.e. a duopolistic Cournot market). Moreover, there are two shareholders, A and B, who belong to country 1 and 2, respectively, and own a reciprocal (mutual) participation in both firms. Therefore, each firm is jointly owned by two shareholders, with shareholder A (B) having the majority of (or at the limit equal) shares, and thus also the control of firm 1 (2). We denote by $m_{2}\left(m_{1}\right)\left(0 \leq m_{1}, m_{2} \leq .5\right)$ the fraction of shares that shareholder A (B) has in firm 2

\footnotetext{
8 In particular, for European Union countries (which make up high share of high-income OECD countries), the restrictions to foreign ownership in the airline sector apply only to foreign investors outside the European Economic Area. However, other European Union countries, for example Greece and Spain, restrict foreign ownership in other sectors, including electricity and media.
} 
(1). As usual in the literature, we assume that the cross-ownership share is exogenously given (see e.g. Reynolds and Snapp, 1986 and Macho-Stadler and Verdier, 1991). Shareholders are assumed to maximise their total profit, which means that the objective function of shareholder $\mathrm{A}$ is

$$
\pi_{A}=\left(1-m_{1}\right) \pi_{1}+m_{2} \pi_{2} .
$$

while the objective function of shareholder B is.

$$
\pi_{B}=m_{1} \pi_{1}+\left(1-m_{2}\right) \pi_{2} .
$$

The two firms face the same constant marginal cost, $z$. Since shareholder A chooses $q_{1}$, while shareholder $\mathrm{B}$ chooses $q_{2}$, then each shareholder (firm) internalizes the fact that both firms compete on quantities. Note that, when the interlocking cross-ownership share is $50 \%$, the profit maximization obtains the monopolistic output (equally shared between firms). ${ }^{9}$ For the sake of simplicity, we assume henceforth an identical two-sided cross-ownership share, $m_{1}=m_{2}=m \in[0, .5] .^{10}$

The governments of Country 1 and 2 provide specific export subsidies, $s_{i}$, to their producers. More precisely, when $s_{i}>0$, the government pays the domestic producer a subsidy to sustain exports; on the other hand, when $s_{i}<0$, the government imposes an export tax to restrict overseas sales. Therefore, firm $i$ 's cost function is linear and described by:

$$
C_{i}\left(q_{i}\right)=\left(z-s_{i}\right) q_{i}
$$

We assume the standard linear inverse demand for each differentiated product, which is (e.g. Singh and Vives, 1984):

$$
p_{i}=a-\gamma q_{j}-q_{i}
$$

where $p_{i}$ denotes price, $q_{i}$ and $q_{j}$ are the two firms' output levels, and $\gamma \in(-1,1)$ represents the degree of substitutability between products. To guarantee non-negativity on output levels, it is assumed that $a \geq z-s_{i}$.

Therefore, profits of firm $i$ can be written as

$$
\pi_{i}=p_{i} q_{i}-\left(z-s_{i}\right) q_{i}, \quad i=1,2 .
$$

The model is a two-stage game, whose timing is as follows. At the pre-play stage, governments decide whether to intervene in trade policy. At stage one, the governments of the exporting countries set the optimal subsidy level to maximise

\footnotetext{
9 The usual assumption that who owns the majority of the shares acquires the right to "manage" the firm's choices implies that, in the present model, $m \leq 0.5$. However, in principle, it would be possible even to postulate that the major shareholder "delegates" the firm's choices to the minor shareholder if this were more convenient for both shareholders. This case is left for further research.

${ }^{10}$ In the real world, the symmetric cross-ownership may represent a very specific case. However, it has been observed that, as La Porta et al. (1999) report, the Allianz Group held 25\% of Münchener Rückversicherung, and vice versa.
} 
social welfare. At stage two, the firms simultaneously, and independently, choose their production levels. As usual, the game is solved by backward induction.

In the present context, the government's export subsidy policy represents the "commitment" that the national exporter increases sales in the third market. Essentially, the provision of a subsidy ensures the profit shift in favor of the national exporter. If the value of profit shifting more than offset the subsidy cost, then the subsidization improves the national welfare. Nonetheless, one cannot permanently presume a government's "commitment" to the strategic trade policy tools. Put differently, if the government lacks commitment, the timing of the game is different, with firms moving first and anticipating (eliciting) the government response in the form of tax or subsidy (see Carmichael, 1987; Leahy and Neary, 1997; Neary and Leahy, 2000; Baghdasaryan and Žigić, 2010; and the survey of Žigić, 2011).

At stage two, each firm chooses its optimal output. From (1), (2) and (5), under profit-maximisation, firm $i$ 's best-reply function is

$$
q_{i}\left(q_{j}\right)=\frac{\left(a-z+s_{i}\right)(1-m)-\gamma q_{j}}{2(1-m)} \geq 0, \quad i, j=1,2, \quad i \neq j .
$$

Inspection of (6) reveals that, under the Cournot assumption, the best-reply functions are downward-sloping when goods are substitutes, i.e. for $\gamma \in(0,1)$, and the product market game is played in strategic substitutes; on the other hand, they are upward-sloping when goods are complements i.e. for $\gamma \in(-1,0)$, and the product market game is played in strategic complements. Moreover, it can be easily verified that the second-order condition for a maximum (concavity) in the stakeholder problem is $\frac{\partial^{2} \pi_{k}\left(q_{i}, q_{j}\right)}{\partial q_{i}^{2}}=2 m-2<0$ for $m \in[0, .5]$ and, therefore,

$$
k=A, B i, j=1,2, \quad i \neq j
$$

it is fulfilled. By solving the system represented by (6) and its counterpart for $j$, we obtain output as a function of subsidy policies:

$$
q_{i}\left(s_{i}, s_{j}\right)=(1-m) \frac{\left[2(1-m)\left(a-z+s_{i}\right)-\gamma\left(a-z+s_{j}\right)\right]}{4\left(1+m^{2}-2 m\right)-\gamma^{2}} \quad i, j=1,2, \quad i \neq j .
$$

Given the outlined hypotheses of the model, it can be easily shown that $q_{i}\left(s_{i}, s_{j}\right) \geq 0$ in the relevant parameter space. As a consequence, profits are as follows 


$$
\begin{aligned}
& \left.\pi_{k}\left(s_{i}, s_{j}\right)=\frac{\left[\begin{array}{r}
4\left(s_{i}-s_{j}\right) m^{3}+\left[2 a(\gamma-1)+2\left(s_{i}-z\right)-10 s_{i}+8 s_{j}+2 z\right] m^{2}+ \\
{\left[\gamma^{2}\left(a-z-s_{i}+2 s_{j}\right)-\gamma\left(3(a-z)+4 s_{i}-s_{j}\right)+4\left(a-z-s_{j}\right)+8 s_{i}\right] m} \\
+\gamma^{2}\left(s_{i}-s_{j}\right)+\gamma\left(a+2 s_{i} s_{j}-z\right)-2\left(a+s_{i}-z\right)
\end{array}\right]}{(m-1)\left[2\left(a+s_{i}-z\right) m+\gamma\left(a-z+s_{j}\right)-2\left(a-z+s_{i}\right)\right]}\right] . \\
& k=A, B \quad i, j=1,2, \quad i \neq j
\end{aligned}
$$

The social welfare $(S W)$ expressions of the two countries are

$$
\begin{aligned}
& S W_{1}=\pi_{A}-s_{1} q_{1} \\
& S W_{2}=\pi_{B}-s_{2} q_{2}
\end{aligned} .
$$

At stage one, each government maximises social welfare ${ }^{11}$ with respect to its subsidy rate for a given subsidy rate of the other government. Standard calculations allow one to derive the reaction functions in subsidy rates:

$$
s_{i}\left(s_{j}\right)=\frac{\left[\left(4 m(1-m)-\gamma^{2}\right)\left[(a-z)(2(1-m)-\gamma)+\gamma s_{j}\right]\right]}{2\left[4\left(1+m^{3}-m^{2}-m\right)-\gamma^{2}(2-m)\right]} .
$$

Moreover, it can be easily verified that the second-order condition for a maximum (concavity) for each government problem is $\frac{\partial^{2} S W_{i}\left(s_{i}, s_{j}\right)}{\partial s_{i}^{2}}=$ $-\frac{2(m-1)^{2}\left[4\left(m^{2}-1\right)(m-1)+\gamma^{2}(m-2)\right]}{(\gamma+2 m-2)^{2}(\gamma-2 m+2)^{2}}<0$ for $m \in[0, .5]$ and $\gamma \in(-1,1), i, j=1,2, \quad i \neq j$ and, therefore, it is fulfilled.

Solving the system represented by (10) and its counterpart for the government $j$, the common subsidy rate at equilibrium is

$$
s_{i}=s_{j}=s=\frac{\left.\left[4 m(1-m)-\gamma^{2}\right)\right](a-z)}{\gamma^{2}+4 m^{2}-2 \gamma-4} .
$$

with $\frac{\partial s}{\partial \gamma}>0$ if $\gamma>2\left(m-1+\sqrt{2 m^{2}-3 m+1}\right)$, and $\frac{\partial s}{\partial m}<0$. The rationale for the first comparative statics is that, if the degree of competition is adequately high (products become less complements/more substitutes), the governments tend to give higher subsidies; on the other hand, a combination of high product complementarity and high passive cross-ownership induce governments to decrease the size of the subsidy to foster a more competitive behaviour of the national champions. With regard to the second comparative statics, the rationale is that the more collusive becomes the behaviour of the national exporting company, the less the government is inclined to disburse public funds to support its expansion.

\footnotetext{
${ }^{11}$ The expressions for $S W\left(s_{i}, s_{j}\right)$ are too long and are omitted here for economy of space.
} 
By exploiting (11) and recalling (7), (8), and (9), after the usual algebra, the equilibrium values of output, profits, and social welfare are derived (where the superscript $\mathrm{S}$ denotes the case in the presence of strategic trade policy):

$$
\begin{gathered}
q_{i}=q_{j}=q^{S}=\frac{2(1-m)(a-z)}{\gamma^{2}+4 m^{2}-2 \gamma-4} . \\
\pi_{A}=\pi_{B}=\pi^{S}=\frac{4[1-m(1-\gamma)](1-m)(a-z)^{2}}{\left(\gamma^{2}+4 m^{2}-2 \gamma-4\right)^{2}} . \\
S W_{i}=S W_{j}=S W^{S}=\frac{2\left[2+2 m(1+\gamma)-4 m^{2}-\gamma^{2}\right](1-m)(a-z)^{2}}{\left(\gamma^{2}+4 m^{2}-2 \gamma-4\right)^{2}} .
\end{gathered}
$$

An analytical inspection of (14) reveals that (1) $\frac{\partial S W_{i}}{\partial \gamma}<0$ in all the relevant parametric range; and (2) $\frac{\partial S W_{i}}{\partial m}>0$ in the area defined by the set of points $(m=$ $0 \cup \gamma=1 \cup m \leq m(\gamma) \equiv \gamma / 2)$ when products are substitutes, and by the set $(m \in$ $(\gamma=-1) \mid 0.134 \leq m<.5) \cup \gamma \in \quad(m=.5) \mid-1 \leq \gamma<-.414) \cup m(\gamma) \equiv 1-$ $\left.\sqrt{\gamma^{2}-2 \gamma} / 2<m\right)$ ) when products are complements, and $\frac{\partial S W_{i}}{\partial m}<0$ in the remaining portions of the relevant parametric space.

Finally, without subsidy policy, i.e. under free-trade (FT), the social welfare is ${ }^{12}$

$$
S W^{F T}=\frac{[1-m(1-\gamma)](1-m)(a-z)^{2}}{(2+\gamma-2 m)^{2}} .
$$

\section{Welfare analysis}

In this section, we compare our results with those of the basic Brander and Spencer model. Conventional wisdom states that social welfare at equilibrium under trade policy $^{13}$ is lower than that under free trade, and we seek to determine if this holds true in the presence of mutual share of cross-ownership.

The standard results of Brander and Spencer assert that (1) the subsidy is always the optimal trade policy instrument, (2) the SPNE of the governments' game is always the subsidy policy, (3) exporters' profits are always higher with the subsidy policy, and (4) social welfare is greater under free trade (resp. under subsidy policy) when products are substitutes (resp. complements). In other words, in the presence of substitute goods, a prisoner's dilemma game structure arises. Essentially, this means that the positive effects of subsidy on profits with complement products always counterbalance the negative effects of subsidy costs. The rationale for this

\footnotetext{
12 The equilibrium outcomes under free trade are easily obtained by setting $s_{i}=s_{j}=0$ in (12)-(15); for economy of space we report only the expression of social welfare, because the other equilibrium expressions are immaterial for our purposes.

13 The strategic profile in which both governments set trade policies is the sub-perfect Nash equilibrium, also in this model, with a mutual share of cross-ownership. The proof is omitted here for brevity.
} 
result is that firms "collude" with complement goods, loosely speaking. That is, by facilitating a larger quantity, subsidies to the exported quantity also imply higher prices and thus higher profits; however, if products are substitutes, a larger output leads to lower prices and profits.

Our investigation begins with the establishment of the following Lemmas.

Lemma 1. The optimal trade policy is.

1. A subsidy when: (i) cross-ownership is very low, for almost any degree of substitutability/complementarity among goods; (ii) cross-ownership is low/mediumlow, for a high degree of substitutability/complementarity among products; and (iii) the level of cross-ownership is medium/medium-high, only for very strong complements and close substitutes;

2. A tax when: (i) goods are very differentiated/weak complement; (ii) when cross-ownership is low/medium-low, for low and intermediate degree of substitutability/complementarity among products; and (iii) the level of cross-ownership is medium/medium-high for almost all levels of product differentiation, i.e. low/ medium-high degrees of substitutability/complementarity.

\section{Proof: see Appendix.}

Note that, in the special case of homogeneous products (i.e. $\gamma=1$ ), the optimal trade policy is always a subsidy, regardless of the level of cross-ownership. This matches the traditional model from Brander and Spencer (1985). Conversely, when products are sufficiently differentiated, the conventional wisdom is reversed.

Lemma 2. Output always decreases in the level of two-sided cross-ownership when products are substitutes, and it can increase when products are sufficiently complementary and the level of cross-ownership is sufficiently large.

\section{Proof: see Appendix.}

Under free trade, output is always decreasing with the level of two-side crossownership. Under trade policy, output can be inversely linked to "more collusion," even under product complementarity.

As expected, profits under trade policy are larger (resp. smaller) than those under free trade if governments set a subsidy (resp. a tax). Moreover, the following Lemma describes the link between profits and cross-ownership under trade policy using.

Lemma 3. Profits decrease with increasing levels of two-sided cross-ownership, except in the case of very strong product complementarity.

\section{Proof: see Appendix.}

To evaluate the impact of cross-ownership on profits, two forces must be considered. On the one hand, increasing participation share within the rival firm reduces output and tends to increase profits because of more collusive behaviour. On 
the other hand, the negative impact of cross-ownership on the trade policy tool reduces the company's profitability. The different impact of those two opposite forces can be analysed through the total derivative of the profit function with respect to $m$ :

$$
\frac{d \pi_{A}}{d m}=\frac{(+/-)}{\partial \pi_{A}} \frac{(+)}{\partial m}+\frac{\partial \pi_{A}}{\partial s_{i}} \frac{\partial s_{i}}{\partial m} \quad \text { for } \quad m \in[0, .5] .
$$

Lemma 3 shows that the first term of the total derivative, the direct effect of cross-ownership, is almost always negative, unless goods are strong complements. This is because, in this case, product complementarity works as an additional collusive element. The second term of the total derivative describes the overall impact of cross ownership on the trade policy instrument. The first element of the second term is standard: the implementation of the trade policy is designed to improve profitability. However, as discussed in the previous section, the second element has a negative effect: subsidies decrease (and taxes increase) with the changes in the level of cross-ownership. It follows that the sign of the second term is unambiguously negative. As a consequence, in almost all relevant parametric ranges of analysis, the total impact of cross-ownership on profits is negative; the negative policy effect more than counterbalances the positive effect of increased collusion.

Dick (1993) provides further insight into the result in Lemma 3. According to that study, the rationale for the substantial decline of the optimal export subsidy that governments provide, even in the presence of small cross-ownership rates, comes from an analysis of a duopoly model. In fact, Brander and Spencer (1985) demonstrate that, in a duopoly framework, the Stackelberg equilibrium arises when a unilateral optimal export subsidy is present.

Under the assumptions of linear demand and constant marginal cost, the (subsidized) leader's profits are $12 \%$ larger than the Cournot equilibrium, while a $44 \%$ decrease in the (non-subsidized) followers' profits occurs. Furthermore, aggregate profits in the industry fall by $16 \%$. Thus, when the domestic government subsidizes the exporter, domestic shareholders obtain a partial share of a minor increase in its profits but also experience a loss of share due to the considerable contraction of the foreign-based firm's profits. The asymmetry in firms' profit reactions decreases the impact of subsidization on domestic shareholder wealth, making an export subsidy less appealing.

Let us define the following social welfare differential:

$$
\begin{aligned}
\Delta & =S W^{S}-S W^{F T} \\
& =\frac{\left\{\begin{array}{r}
{\left[-\gamma^{3} m-4 \gamma m^{3}+5 \gamma^{2} m-4 \gamma m^{2}+4 m^{3}-3 \gamma^{2}+12 \gamma m-8 m^{2}-4(\gamma-m)\right]} \\
\left(\gamma^{2}+4 m^{2}-4 m\right)(1-m)(a-z)^{2}
\end{array}\right\}}{\left(\gamma^{2}+4 m^{2}-2 \gamma-4\right)^{2}(2+\gamma-2 m)^{2}} .
\end{aligned}
$$

Moreover, let us define the following welfare differentials with regard to the consumers $(C S)$ and the world as a whole $(W S W)$ : 


$$
\begin{aligned}
\Delta_{C S} & =C S^{S}-C S^{F T} \\
& =\frac{\left(\gamma^{2}+4 m^{2}-4 \gamma+4 m-8\right)\left(-\gamma^{2}-4 m^{2}+4 m\right)(1-m)^{2}(a-z)^{2}(1+\gamma)}{\left(\gamma^{2}+4 m^{2}-2 \gamma-4\right)^{2}(2+\gamma-2 m)^{2}}
\end{aligned}
$$

$\Delta_{W S W}=W S W^{S}-W S W^{F T}=$

$\frac{\left(\gamma^{3}-4 \gamma+3 \gamma^{2}+8+4 m^{3}(\gamma-3)+8 m^{2}(\gamma+2)+m\left(\gamma^{3}-7 \gamma^{2}-8 \gamma+4\right)\left(-\gamma^{2}-4 m^{2}+4 m\right)(1-m)^{2}(a-z)^{2}\right.}{\left(\gamma^{2}+4 m^{2}-2 \gamma-4\right)^{2}(2+\gamma-2 m)^{2}}$,

where

$$
\begin{gathered}
C S^{S}=\frac{4(1+\gamma)(1-m)^{2}(a-z)^{2}}{\left(-2 \gamma+\gamma^{2}-4+4 m^{2}\right)^{2}} \\
C S^{F T}=\frac{(1+\gamma)(1-m)^{2}(a-z)^{2}}{(2+\gamma-2 m)^{2}} \\
W S W^{S}=\frac{4\left(3+m+\gamma(1+m)-\gamma^{2}-4 m^{2}\right)(1-m)(a-z)^{2}}{\left(-2 \gamma+\gamma^{2}-4+4 m^{2}\right)^{2}} \\
W S W^{F T}=\frac{(3+\gamma(1+m)-3 m)(1-m)(a-z)^{2}}{(2+\gamma-2 m)^{2}}
\end{gathered}
$$

Closer analytical inspection of (16), (17), and (18) provides the following results.

Result 1 Both countries benefit from the strategic trade policy:

a. In the case of complement goods when:

(i) Cross-ownership is extremely low for almost any degree of complementarity,

(ii) the level of cross-ownership is low/medium-low for intermediate-high degrees of complementarity among products, (iii) the level of cross-ownership is medium/medium-high for strong degrees of product complementarity, and (iv) the level of cross-ownership is high only for very strong product complementarity;

b. In the case of substitute goods when:

(i) Cross-ownership is extremely low for differentiated products, (ii) the level of cross-ownership is low/medium-low for intermediate degrees of product differentiation, (iii) the level of cross-ownership is medium/medium-high for intermediate-high degrees of product differentiation, and (iv) the level of crossownership is high for close substitutes.

On the other hand, both countries benefit from free trade:

a. In the case of complement goods when:

(i) Cross-ownership is very low, only in the case of low degrees of complementarity; (ii) the level of cross-ownership is low/medium-low for 
low degrees of complementarity among products, (iii) the level of crossownership is medium/medium-high for low-intermediate degrees of product complementarity, and (iv) the level of cross-ownership is high for almost any degree of complementarity;

b. In the case of substitute goods when:

(i) Cross-ownership is extremely low for medium-close substitute products, (ii) the level of cross-ownership is low/medium-low for very differentiated products and close substitutes, (iii) the level of cross-ownership is medium/ medium-high for differentiated products and very close substitutes, and (iv) the level of cross-ownership is high for differentiated products.

Proof: see Appendix.

Fig. 1 gives the full graphical representation of Result 1 , showing the parametric regions in the plane $(\gamma, m)$ for which $\Delta \frac{>}{<}$. The intuition behind Result 1 is detailed below. Preliminarily, we observe that, under free trade, the national social welfare (which is equal to profits) is always increasing in $m$, that is:

$$
\frac{\partial S W^{F T}}{\partial m}=\frac{\partial \stackrel{+}{\pi^{F T}}}{\partial m}
$$

The summary of the cross-ownership's effect analysis on the social welfare under trade policy is given by the following expression (from Lemmas 1, 2, and 3), in the case of product substitutes:

$$
\left.\frac{\partial S W^{S}}{\partial m}\right|_{\gamma>0}=\frac{\partial \pi^{S}}{\partial m}\left(\frac{\partial^{-}}{\partial m} q+\frac{\partial q}{\partial m}^{+}{ }^{-}\right) .
$$

Under trade policy, starting from $m=0$, the sign of the element inside the brackets on the right-hand side of (19) is necessarily negative. This indicates that the reduction in the cost of subsidy always outweighs the reduction of profits so that social welfare is increasing with $m$, although it is lower than social welfare under free trade.

For a given level of product differentiation, when $m$ starts to increase, social welfare under trade policy (in the form of an export subsidy) increases in $m$ (Region IV). As such, the collusive behaviour in the product market is relatively low, and governments strategically subsidize their exporters to help them to gain market shares. The reduction of the subsidization cost still outweighs the profit contraction of the national shareholder; nonetheless, the social welfare under trade policy does not exceed that under free trade.

On the other hand, an increase in $m$ induces governments to set taxes. This first threshold level exists because a tax (which induces a quantity reduction) supports prices to the extent that the balance between lower quantity and higher price determines a profit loss that is less than the increment of the tax revenue. However, trade policies improve the countries' welfare (Region III,A), but only if the share of mutual cross-ownership is not too high. In fact, the sign of the element inside the 


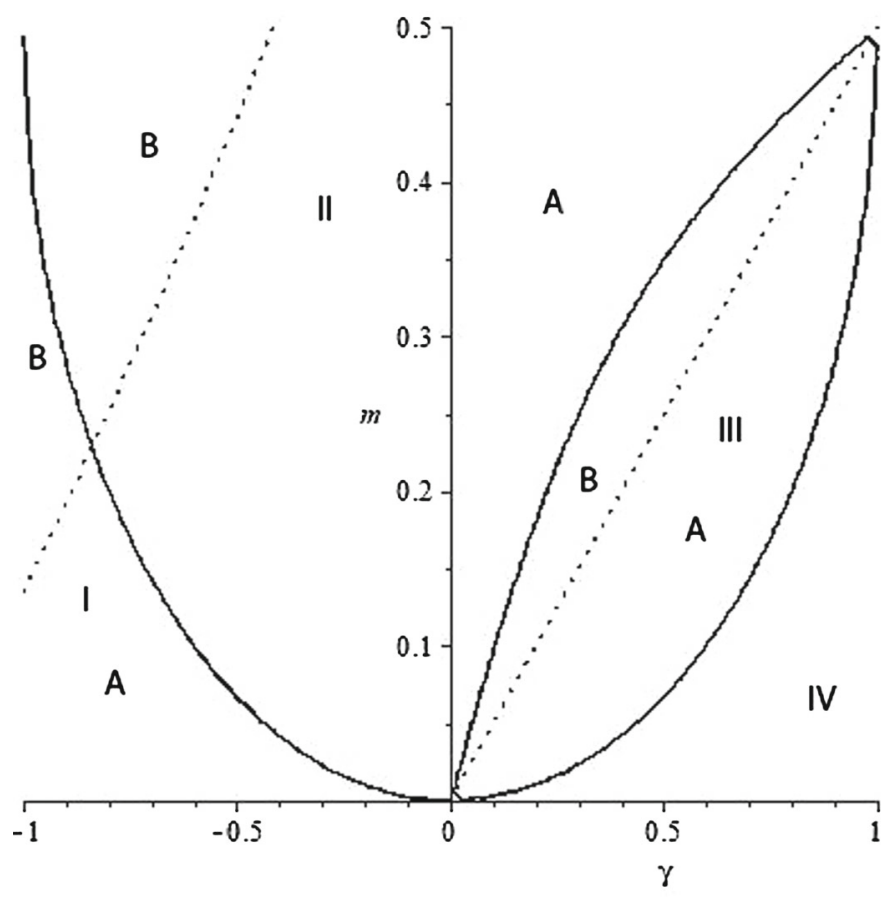

Fig. 1 Plots of the differential $\Delta=0, \Delta_{C S}=0, \Delta_{W S W}=0$ and $s=0$. Legend: Region I: $\Delta>0$, $\Delta_{C S}>0, \Delta_{W S W}>0$ and $s>0$; in $A, \frac{\partial S W^{S}}{\partial m}<0$, in $B, \frac{\partial S W^{S}}{\partial m}>0$; Region II: $\Delta<0, \Delta_{C S}<0, \Delta_{W S W}<0$ and $s<0$; in $A, \frac{\partial S W^{S}}{\partial m}<0$, in $B, \frac{\partial S W^{S}}{\partial m}>0$; Region III: $\Delta>0, \Delta_{C S}<0, \Delta_{W S W}<0$ and $s<0$; in $A$, $\frac{\partial S W^{S}}{\partial m}>0$, in $B, \frac{\partial S W^{S}}{\partial m}<0$; Region IV: $\Delta<0, \Delta_{C S}>0, \Delta_{W S W}>0$ and $s>0, \frac{\partial S W^{S}}{\partial m}>0$

brackets on the right-hand side of (19) is ambiguous if the value of $m$ is adequately low, and the impact on social welfare is still positive for an increasing $m$.

When the level of cross-ownership becomes relatively high, the sign of the element in the brackets on the right-hand side of (19) becomes positive, and social welfare begins to reduce in $m$ (Region III,B). Yet, the magnitude of the negative impact on the social welfare of increasing cross-ownership is low, so the implementation of the trade policy guarantees a welfare level higher than that under free trade.

The social welfare under free trade always increases in $m$, while that under trade policy decreases when $m$ is sufficiently large. Therefore, it follows that a second threshold level of $m$ must exist, beyond which free trade again becomes welfare preferred (Region II,A). This second threshold level of $m$ emerges as follows: since the degree of "collusion" implied by the cross-ownership (that is, the restriction of quantity) is high by itself, then a taxation that reduces further quantities generates a level of tax revenue less than the profit loss.

The degree of product differentiation serves to expand the area in which the government subsidizes firms as long as goods are close substitutes. Meanwhile, when goods are differentiated, the area of taxation is predominant. This is because, when goods are close substitutes, the competition in the third market intensifies. Thus, 
the government supports the firm in reducing its cost to gain further market shares. When goods are differentiated, firms reduce output to such an extent that their final prices are sufficiently high to determine that governments can increase tax revenues.

Note that the case of optimal taxes in this model, existing under quantity competition and reciprocal cross-ownership, has welfare properties that differ from those in the case of optimal taxes under price competition, as analysed by Eaton and Grossman (1986). In the case of that study, countries' welfare with strategic trade policy is larger than that under the laissez-faire model, while in the present case, beyond a certain level of cross-ownership, taxation is harmful in comparison to laissez-faire. Taxation is always damaging for consumers and world welfare because it reduces quantities, as in the model by Eaton and Grossman (1986). So, when the cross-ownership share is high, the equilibrium trade policies not only implies a prisoner's dilemma outcome for the producing country but also a welfare damage for consumer and the world as a whole. That is, in contrast with both cases of equilibrium trade policies under quantity (e.g. Brander and Spencer, 1985) and price competition (e.g. Eaton and Grossman, 1986), a "lose-lose" outcome occurs. This is why trade policy, which is Pareto-inferior in the absence of cross-ownership, becomes optimal when mutual cross-ownership is sufficiently high. Firms (and governments) internalize the impact of trade policy on foreign firms (because domestic firms are shareholders of foreign firms). This in turn reduces the negative effects of market share rivalry and business stealing. However, when the mutual cross-ownership becomes relatively too high, it becomes again Pareto-inferior.

In the case of product complements, the summary of the cross-ownership's effect analysis on the social welfare under trade policy is given by the following expression (from Lemmas 1, 2, and 3):

$$
\left.\frac{\partial S W^{S}}{\partial m}\right|_{\gamma>0}=\frac{\partial \pi^{S}}{\partial m}\left(\frac{\frac{-}{\partial}}{\partial m} q+\frac{\partial q}{\partial m}^{+/-} s\right) .
$$

Also, in terms of product complements, the use of (20) enables us to apply the line of reasoning developed above regarding product substitutes to explain how and why the presence of cross-ownership brings upon the inefficiency of public intervention. This is in sharp contrast to the conventional result. For complement goods, only one threshold delimiting the area in which strategic trade has the characteristic of a prisoner's dilemma game exists. Indeed, the degree of product complementarity allows firms to keep prices high; the government strategically subsidizes companies to gain market shares. However, the profit expansion of the national company more than counterbalances the subsidization cost, so the social welfare under trade policy is higher than that under free trade. As a consequence, an equivalent of Region IV for substitute products is missing for the complementary ones. ${ }^{14}$

\footnotetext{
${ }^{14}$ In fact, in both cases of equilibrium trade policies under quantity (e.g. Brander and Spencer, 1985) and price competition (e.g. Eaton and Grossman, 1986), if products are complements, then trade policies (i.e. subsidies and taxes, respectively) are always welfare improving in comparison with the laissez-faire model. In the present model, they are in most parametric spaces welfare-reducing, especially when the cross-ownership share is high.
} 
Result 2 The consumer's surplus and the world's social welfare are higher (lower) under free trade than under subsidization in Regions II and III (resp. in regions I and IV).

Proof: see Appendix.

Figure 1 gives a full graphical representation of Result 2, showing the parametric regions in the plane $(\gamma, m)$, for which it is $\Delta_{C S}>0$ and $\Delta_{W S W}>0$. In the standard model, (1) when products are substitutes, consumers and world society benefit, while producer countries are harmed from subsidisation (i.e., there is a conflict of interest between exporting countries and world consumers [and the world as a whole] with regard to the export subsidies). ${ }^{15}$ Furthermore, (2) when products are complements, all agents benefit from subsidisation in the presence of mutual crossownership in Region II (in which products are either substitutes or complements) and all agents are harmed from subsidisation. However, in Region III, there is again a conflict of interest, but for the opposite reason, with respect to the conventional wisdom (consumers and world society are harmed while exporting countries benefit from subsidisation). ${ }^{16}$

In summary, this study identifies the parametric regions in which the total reversal of the basic Brander and Spencer model is obtained with regard to exporting countries, the consumer's surplus, and the worldwide social welfare. ${ }^{17}$

\footnotetext{
15 Following the traditional line of research, this paper has focused the analysis on the domestic markets whose exporters sell the products into the third market, abstracting from the possibility that the importing country put in place its own trade policy. On the whole, the third market can be intended as part of the rest of the world (more than a single government). Brander and Spencer (1984) have considered the case of a single importer country and studied the exogenous equilibrium in which the exporting governments fix the optimal subsidies and the importing government fixes the optimal tariff. However, the extended game between three governments is analytically complex (there are 8 strategic situations to analyse). Deriving the endogenous equilibrium would require a separate study that is left for future research.

16 The current model has considered the symmetric cross-ownership case, i.e. $m_{1}=m_{2}=m$. In general, however, $m_{1} \neq m_{2}$. The model with asymmetric parameters is analytically difficult to treat; however, some insights can be derived from the polar case in which one company has a minority stake in the rival, while the other does not, analyzed in Fanti and Buccella (2016b). Under Cournot competition, the asymmetric passive cross-ownership alters the choice of the strategic trade policy instrument of the participating and participated firms' governments, the game equilibria, and their efficiency properties. In fact, if the share of cross-ownership is adequately large, the government of the participated firm finds it optimal to tax exports. Furthermore, beyond a sufficiently high threshold, cross-ownership modifies the equilibrium from the activist regime for both countries to an asymmetric regime in which only the participating firm's government intervenes. In addition, in the case that both governments intervene in equilibrium, the classical prisoner's dilemma structure of the game might disappear.

17 Note that, as in Brander and Spencer (1985), in this model, the only competition between domestic and foreign firms occurs in third-country markets. However, it is possible that the goods exported are also consumed in the home market. In such an instance, given the imperfect competition context, it may be argued that export subsidies can work for a diversion of the supply from the domestic to the foreign market, thus generally driving up the domestic price and penalizing home consumption. Therefore, this could have adverse implications for national economic welfare, and one must consider that, in this type of model, social welfare does not include home consumption of goods: in the words of Grossman (1986, p. 58), "the clear-cut Brander-Spencer finding becomes theoretically ambiguous as soon as the welfare of domestic consumers is taken into account.".
} 


\section{Extensions}

We briefly describe here some extensions of the main model. Analytical details are available upon request from the authors in the supplemental materials.

\subsection{Endogenous choice of the cross-ownership share}

First, we have considered the endogenous choice of the cross-ownership share that a firm has of the rival. ${ }^{18}$ In this case, the model is structured as a three-stage game in which, at stage two, each firm $i$ chooses the optimal level of cross-ownership $m_{j}, i \neq j, i, j=1,2$. Unfortunately, the first-order condition at stage 2 leads to an extremely complex analytical expression without closed-form solutions. To derive some intuition, we proceeded with some numerical simulations for the case of free trade, i.e. $s_{1}=s_{2}=0$. We have obtained that, under free trade, in the presence of endogenous choice of the share of cross-ownership, an inverse U-shaped relation exists between the degree of complementarity/substitutability among products and the level of $m$, with $m_{i}=m_{j} \geq 0.5$. In other words, each shareholder retains a minority stake in the national company and a majority stake in the foreign company.

The intuition behind this result is as follows. A company that enters into a long equity position in the rival takes into account the impact of its production decision on the rival's profit. Therefore, the firm acts less aggressively and restricts its output leading the profit of the rival to increase. Holding a majority stake in the foreign rival, the income of the national shareholder increases as well. Thus, a reciprocal majority stake induces each shareholder to restrict output in the firm that controls in order to gain larger incomes.

As a consequence, one may conjecture that the provision of a subsidy would expand the national production; nonetheless, given that the majority stake is retained by a foreign shareholder, this policy can most plausibly increase its income and, therefore, the welfare of the foreign country. As a consequence, one should expect the imposition of an export tax as the government's optimal trade policy. ${ }^{19}$

\footnotetext{
18 An extensive analysis of endogenous cross-holdings can be found in Qin et al. (2017).

19 As a referee has rightly indicated, the model in which the choice of $m$ is endogenous presents a weakness in the current specification. The result that the endogenous equilibrium level of "passive" cross-ownership is larger than 50\% is unrealistic. In real world, there are examples of international partial ownership arrangements in which the acquiring firm owns a stake in the acquired firm, which can be a majority one but less than 100\%, obtaining its corporate control (see Foros et al., 2011 about the pay-TV markets in Norway and Sweden). Our proposed framework is built such that shareholder A controls firm $i$ based in country $i$ and chooses $q_{i}$, and it is subsidized/taxed by government $i$. Because the endogenous interlocking ownership share in equilibrium is larger than $50 \%$, it should be more appropriate to assume that shareholder A chooses $q_{j}$ and not $q_{i}$ (and vice versa for the rival). The point is that, in a two-stage game structure solved by backward induction, one cannot infer a priori that in equilibrium $m \geq 0.5$. Thus, this specification leads to an interesting theoretical result with, unfortunately, a limited practical use. Nonetheless, we note that, in line of principle, a firm, although having a majority of shares in the rival firm, may give up control because either it considers the possession of other firm's shares as a pure financial investment, or it is unable to manage the other firm due to the lack of specific managerial skills and knowledge (especially when firms are located in very different countries). Even so, this model specification may serve as a base to develop a more complex, and realistic model in which the presence of asymmetries (such as in factors' productivity and, therefore, production costs) can lead shareholders to
} 


\subsection{Costly public funds}

In the basic model, we have considered that public funds are not costly and the trade subsidy (or tax) is a pure transfer between the government and the firm. In an extension, we have analyzed the case of costly public funds. Following Neary (1994) and Collie (2000), the social welfare function is now of the form $S W_{i}=\pi_{k}-\lambda s_{i} q_{i}, i=1,2 ; k=A, B$, where $\lambda \geq 1$ is the opportunity cost of government revenue, assumed symmetric among countries. The opportunity cost changes the main findings as follows. With regard to the optimal export trade policy, a higher $\lambda$ decreases the parametric area in which the subsidy provision is optimal and, eventually, for a sufficiently high $\lambda$, an export tax is the only optimal trade policy. A comparison of the (exogenously given equilibria of the) social welfare levels under the strategic trade policy and free trade shows that an increasing value of $\lambda$ enlarges the parametric area in which the social welfare differential $\Delta=$ $S W^{S}-S W^{F T}>0$ applies in the presence of an export tax (i.e. Region III in Fig. 1 tends to expand, Region I and IV disappear), while free trade leads to superior outcomes only for strong complementary goods (i.e. Region II shrinks and moves to the left). This result suggests that a government of a country in which firms are export-oriented can find beneficial to introduce in the exporting sector the distortionary tax to collect revenues that, eventually, could be employed in other sectors of the economy.

\subsection{Segmented markets}

In the real world, it is often observed that firms enter each other's markets. Therefore, we have considered an alternative framework of competition represented by two segmented markets, each one with a national firm that sells products in the domestic as well as the foreign market and a national government that sets the export subsidy/tax trade policy, which now includes the national consumers in its welfare function. The product demand functions are linear, and the timing of the game is as in the basic model. The main findings of this specification are as follows.

First, it has been found that the optimal trade policy tool of a country is independent of the trade policy tool of the rival country. In fact, it depends only on the degree of product differentiation and the cross-ownership level.

A conceivable explanation can be as follows. A standard result in segmented markets model is that firms tend to dampen the export price to penetrate the foreign market (increase of foreign sales /market shares). Subsidization would further depress the export price. The inclusion of the consumer surplus into the governments' objective precisely offset this extra strategic component in the selection of the optimal subsidy which, ultimately, depends only on the market

Footnote 19 continued

choose endogenously $m_{i} \neq m_{j}$, with one shareholder that could retain, in equilibrium, a majority stake in the rival. This is left for future research. 
parameters. $^{20}$ The optimal export subsidy/tax trade policy qualitatively mirrors that of Lemma 1.

Second, when comparing the (exogenously given equilibria of the) social welfare level under the strategic trade policy with that under free trade, preliminary results show that: (1) with complementary goods, Result 1 is qualitatively confirmed; however, (2) with substitute goods, a relevant difference arises. In fact, when the national governments' optimal trade policy is to tax exports in their home-market, the social welfare under free trade is always higher than under strategic trade policy, while when the national governments' optimal trade policy is to subsidize exports in their home-market, the social welfare under strategic trade policy is always higher than under free trade. Therefore, both countries benefit in terms of social welfare under strategic trade policy only in the presence of subsidies. A plausible explanation is that cross-ownership has a "pro-collusive" effect, so that, when taking into account consumer surplus, a government might find it optimal to choose a transfer when products tend to be substitutes. On the other hand, when products are differentiated, to tax exports may induce firms to produce a larger amount of goods for the domestic markets.

\subsection{Bertrand competition}

In the case of a Bertrand duopoly, the presence of mutual cross-ownership can create a parametric region (especially when the degree of product differentiation is intermediate) in which the conventional wisdom is reversed, in the sense that policy activism becomes harmful for all agents. Therefore, the result by Eaton-Grossman (1986) is sharply modified by the presence of mutual cross-ownership. In particular, a tax policy under price competition may be no longer welfare-preferred for both countries. These findings contrast the conventional wisdom that the Nash equilibrium is to tax exports, which is efficient for both exporting countries and in which consumers lose and the world welfare declines. It is shown that, when the share of mutual cross-ownership is sufficiently high (and products are not too close to be perfect substitutes), both countries would benefit (welfare-preferred) at equilibrium to abstain from intervening (i.e. a laissez-faire regime instead of taxing exports); however, the SPNE of the game between governments is always given by the taxing solution. As a consequence, a prisoner's dilemma outcome appears also

\footnotetext{
${ }^{20}$ As a referee has observed, this result may rely on the precise assumption of demand function linearity. The introduction of different functional forms, for instance an iso-elastic demand, can alter it. Also convex cost functions could probably have an impact on this result. However, the increased analytical complexity of the model would require an in-depth investigation which is left for future research.
} 
under price competition and, since consumers of the third market and the world as a whole again continue to be damaged by the export tax policy, then such a policy becomes a "lose-lose" choice. $^{21}$

\section{Conclusions}

This paper revisited the issue of the strategic trade policy intervention by governments to support their exporter firms, extending Brander and Spencer's classical model to the case of interlocking cross-ownership. The recent increasing globalisation of economies has extended not only the volume of goods and services traded but also the international acquisition of financial assets by firms such as (often non-controlling) shares of other firms. We have shown that the implementation of a strategic trade policy can be a Pareto-superior policy for a limited range of the firms' cross-ownership parameter. That is, depending on the degree of product competition, the social welfares of the exporting countries are higher than under free trade. In particular, we have found that the policy intervention with crossownership (1) may assume the form of a tax if the share of cross-participation is adequately large, and (2) leads to a Pareto-superior (resp. Pareto-inferior) equilibrium provided that products are neither too substitutes nor too differentiated (resp. not too complements).

With regard to the welfare analysis, the public intervention through an export tax-which is optimal if the share of mutual cross-ownership is sufficiently highimproves countries' welfare only if that mutual minority share is not too high. In fact, in the latter case, since the degree of "collusion" (the quantity restriction) implied by the cross-ownership is high by itself, then a taxation reducing further quantities brings upon a level of tax revenue less than the profit loss.

These findings provide the insight that, in the presence of cross-participation between rival companies, the unilateral government trade policy intervention can be optimal because, even in the case of the rival government's retaliation, the national welfares of the exporting countries are superior than to those under free trade, though only for appropriate degrees of product competition.

Another insight that arises from the current analysis is the following. If governments are forced to reduce/eliminate explicit subsidies as in the case of the aviation and transport sector because of supranational bodies interventions (e.g., the WTO), then firms to penetrate foreign markets have to buy participations in rivals,

\footnotetext{
21 As a referee has correctly pointed out, a government can use other (fiscal) policy tools to influence the behaviour of shareholders such as the imposition of a corporate tax on companies in each country. Although a corporate tax is not a classical trade policy instrument such as the subsidy/export tax, which represents the main focus in this paper, we have investigated this model specification. The key findings are that, in the relevant parametric space: (1) an optimal corporate tax always exists that governments can impose on domestic firms to maximize social welfare, (2) this optimal corporate tax has an inverted U shaped relation with respect to the degree of product differentiation for each level of cross ownership, and (3) the social welfare with corporate tax is higher than without for combinations of high complementary goods and low minority stakes and, as long as the degree of substitutability increases, for higher shares of the minority stakes.
} 
which translates in minority participations when the interested sector is subject to governmental restrictions on foreign participations.

This implies that the well-known debate about the pro and cons of "neomercantilist" policies pioneered by the Brander and Spencer's approach in the eighties may be resurrected and enriched under the current phenomenon of the "financial" globalisation also of the property shares of many exporting firms.

Moreover, our theoretical finding offers to econometricians a testable implication that in sectors/countries in which trade policies are put in place, cross-ownership should be less often detected. ${ }^{22}$

Future lines of research should conduct an investigation of a more extend game framework considering the presence managerial firms, network industries, R\&D investments, and the presence of unionised labour market institutions.

\section{Appendix}

\section{Proof of Lemma 1}

In the relevant part of the $(\gamma, m)$-plane, the optimal trade policy is an export subsidy, $s \geq 0$, in the area delimited by the set of points $\left(m=0 \cup m \leq m^{\circ}(\gamma) \equiv 1 / 2\left(1-\sqrt{1-\gamma^{2}}\right)\right)$, while it is an export tax, $s<0$, in the area defined by the set of points $\left(m^{\circ}(\gamma) \equiv 1 / 2\left(1-\sqrt{1-\gamma^{2}}\right)<m \cup m=1 / 2\right)$ (see also Fig. 1).

\section{Proof of Lemma 2}

Differentiation of (12) reveals that $\frac{\partial q^{S}}{\partial m}=\frac{2(a-z)\left[\gamma^{2}-2 \gamma-4(1-m)^{2}\right]}{\left[\gamma^{2}-2 \gamma-4\left(1-m^{2}\right)\right]^{2}}$. As a consequence, in the relevant $(\gamma, m)$-plane, it can be verified that $\frac{\partial q^{S}}{\partial m} \geq 0$ in the area delimited by the following set of points

$$
\begin{aligned}
(m= & 0 \cup \gamma=1 \cup \gamma \in(m=1 / 2) \mid 1-\sqrt{2} \leq \gamma<1 \cup m \leq m^{\circ \circ}(\gamma) \\
& \left.\equiv\left(1-1 / 2 \sqrt{\gamma^{2}-2 \gamma}\right) \cup m \in(\gamma=-1) \mid 0 \leq m<1-(\sqrt{3} / 2)\right)
\end{aligned}
$$

while it is found that $\frac{\partial q^{S}}{\partial m}<0$ in the area defined by the set of points

$$
\begin{aligned}
(\gamma & \in(m=1 / 2) \mid-1 \leq \gamma<1-\sqrt{2} \cup\left(1-1 / 2 \sqrt{\gamma^{2}-2 \gamma}\right) \\
& \left.\left.\equiv m^{\circ \circ}(\gamma)<m \cup m \in(\gamma=-1) \mid 1-(\sqrt{3} / 2) \leq m \leq 1 / 2\right)\right) .
\end{aligned}
$$

\footnotetext{
${ }^{22}$ We thank an anonymous referee for having pointed out the issue of the empirical evidence.
} 


\section{Proof of Lemma 3}

Differentiation of the profit expression in (13) leads to $\frac{\partial \pi^{S}}{\partial m}=\frac{4(a-z)^{2}(2-\gamma-2 m)\left[\gamma^{2}(2 m-1)+2 \gamma\left(1-2 m^{2}\right)-4(1-m)^{2}\right]}{\left[\gamma^{2}-2 \gamma-4\left(1-m^{2}\right)\right]^{3}}$. An analytical inspection shows that, in the relevant $(\gamma, m)$-plane, the functional relation between cross-ownership and product differentiation is as follows:

$$
m^{\circ 00}(\gamma)=\left\{\begin{array}{c}
\frac{4-\gamma^{2}-\sqrt{\gamma^{4}-4 \gamma^{3}+4 \gamma^{2}+8 \gamma}}{4(1-\gamma)} \text { for } \gamma \in[-.93,-1) \text { and } m \in(0,2 / 5] \\
\frac{4-\gamma^{2}+\sqrt{\gamma^{4}-4 \gamma^{3}+4 \gamma^{2}+8 \gamma}}{4(1-\gamma)} \text { for } \gamma \in(-.93,-1) \text { and } m \in(2 / 5,1 / 2]
\end{array}\right.
$$

As a consequence, $\frac{\partial \pi^{s}}{\partial m} \geq 0$ in the area delimited by the following set of points $\left.\left(m=0 \cup \gamma=1 \cup m=1 / 2 \cup m \leq m^{\circ \circ}(\gamma) \cup m \in(\gamma=-1) \mid 0 \leq m<1 / 4\right)\right)$, while it is found that $\frac{\partial \pi^{s}}{\partial m}<0$ in the area defined by the set of points $\left(m^{\circ \circ \circ}(\gamma) \leq m \cup m \in(\gamma=-1) \mid 1 / 4<m<1 / 2\right)$.

\section{Proof of Result 1}

The equation $\Delta=0$, where $\Delta$ is as defined in (16), has 6 analytical solutions, 4 real and 2 imaginary. However, among the real solutions, only two fall into the relevant $(\gamma, m)$-plane, i.e. $m^{\circ}(\gamma) \equiv 1 / 2\left(1-\sqrt{1-\gamma^{2}}\right)$ and

$$
m^{\circ 000}(\gamma)=\frac{\Gamma^{2}-2(2-\gamma) \Gamma-3 \gamma^{4}+18 \gamma^{3}+25 \gamma^{2}-8 \gamma+4}{6(\gamma-1) \Gamma}
$$

where

$$
\Gamma \equiv \sqrt[3]{\begin{array}{r}
3 \gamma(\gamma-1)(1+\gamma) \sqrt{3} \sqrt{\gamma^{6}-18 \gamma^{5}+88 \gamma^{4}-22 \gamma^{3}-193 \gamma^{2}+32 \gamma-32}+9 \gamma^{5} \\
-117 \gamma^{4}-125 \gamma^{3}+33 \gamma^{2}-24 \gamma+8
\end{array}} .
$$

This generates four regions in the $(\gamma, m)$-plane, as Fig. 1 shows. An in-depth analytical inspection reveals that:

a) for $\gamma \in(-1,0], \Delta \geq 0$ in Region I in Fig. 1, defined by the set of points $\left(m=0 \mid \gamma \in(-1,0] \cup m \leq m^{\circ}(\gamma) \equiv 1 / 2\left(1-\sqrt{1-\gamma^{2}}\right)\right)$;

b) for $\gamma \in[0,1), \Delta \geq 0$ in Region III in Fig. 1, defined by the set of points $\left(1 / 2\left(1-\sqrt{1-\gamma^{2}}\right) \equiv m^{\circ}(\gamma) \leq m \leq m^{\circ \circ \circ}(\gamma)\right)$.

\section{Proof of Result 2}

The equations $\Delta_{C S}=0$ and $\Delta_{W S W}=0$ defined in (17) and (18) have only one relevant solutions in the significant $(\gamma, m)$-plane, i.e. $m^{\circ}(\gamma) \equiv 1 / 2\left(1-\sqrt{1-\gamma^{2}}\right)$. An analytical inspection shows that $\Delta_{C S} \geq 0$ and $\Delta_{W S W} \geq 0$ in the area delimited by 
the set of points $\left(m=0 \cup m \leq m^{\circ}(\gamma) \equiv 1 / 2\left(1-\sqrt{1-\gamma^{2}}\right)\right)$ corresponding to Regions I and IV in Fig. 1, while $\Delta_{C S}<0$ and $\Delta_{W S W}<0$ in the area delimited by the set of points $\left(m^{\circ}(\gamma) \equiv 1 / 2\left(1-\sqrt{1-\gamma^{2}}\right)<m \cup m=1 / 2\right)$ corresponding to Regions II and III in Fig. 1.

Supplementary Information The online version contains supplementary material available at https://doi. org/10.1007/s00712-021-00745-9.

Acknowledgements We are extremely indebted to the Editor-in-Chief, Giacomo Corneo, and three anonymous referees for their extensive and useful comments, suggestions and remarks that have helped us to improve the quality and clarity of this paper. The usual disclaimer applies.

Open Access This article is licensed under a Creative Commons Attribution 4.0 International License, which permits use, sharing, adaptation, distribution and reproduction in any medium or format, as long as you give appropriate credit to the original author(s) and the source, provide a link to the Creative Commons licence, and indicate if changes were made. The images or other third party material in this article are included in the article's Creative Commons licence, unless indicated otherwise in a credit line to the material. If material is not included in the article's Creative Commons licence and your intended use is not permitted by statutory regulation or exceeds the permitted use, you will need to obtain permission directly from the copyright holder. To view a copy of this licence, visit http:// creativecommons.org/licenses/by/4.0/.

\section{References}

Alley W (1997) Partial ownership arrangements and collusion in the automobile industry. J Ind Econ 45:191-205

Amundsen ES, Bergman L (2002) Will cross-ownership re-establish market power in the Nordic power market? Energy J 23:73-95

Baghdasaryan D, Žigić K (2010) Tariffs, market conduct, and government commitment: policy implications for developing countries. Econ Transit 18:91-122

Bank of Italy (2008) The evolution of ownership and control structure in Italy in the last 15 years, mimeo (https://www.bancaditalia.it/pubblicazioni/altri atticonvegni/2008-corporategovernanceita/ evolution_ownership_control_structures.pdf).

Barcena-Ruiz JC, Campo ML (2012) Partial cross-ownership and strategic environmental policy. Resour Energy Econ 34:198-210

Barcena-Ruiz JC, Olaizola N (2007) Cost-saving production technologies and partial ownership. Econ Bull 15:1-8

Bebchuk LA, Kraakman R, Triantis G (2000) Stock pyramids, cross-ownership, and dual class equity: the mechanisms and agency costs of separating control from cash-flow rights. In: Morck RK, Randall $\mathrm{K}$ (eds) Concentrated corporate ownership. University of Chicago Press, Chicago , pp 295-318

Berglof E, Perotti E (1994) The governance structure of the Japanese financial keiretsu. J Financ Econ 36:259-284

Brander JA (1981) Intra-industry trade in identical commodities. J Int Econ 11: 1-14.

Brander JA (1986) Rationales for strategic trade and industrial policy. In Krugman P., ed., Strategic trade policy and the new international economics, The MIT Press, Cambridge

Brander JA (1995) Strategic trade policy. In Grossman GM and Rogoff K eds., Handbook of international economics, vol. 3, pp 1395-1455. Elsevier, London.

Brander JA, Spencer BJ (1984) Export subsidies and international market share rivalry. In: NBER working paper series no. 1464 .

Brander JA, Spencer BJ (1985) Export Subsidies and international market share rivalry. J Int Econ 18:83-100 
Brander JA, Spencer B (1988) Unionized oligopoly and international trade policy. J Int Econ 24:217-234

Cai D, Karasawa-Ohtashiro Y (2015) International cross-ownership of firms and strategic privatization policy. J Econ 116(1):39-62

Carmichael CM (1987) The control of export credit subsidies and its welfare consequences. J Int Econ 23:1-19

Danish Competition and Consumer Authority (DCCA) (2017) WHEN COMPETITORS OWN (PARTS OF) EACH OTHER Impact of minority shareholdings on effective competition. Well-Functioning Markets 3/2017. DCCA Articles, Available on line at https://www.en.kfst.dk/media/50990/ minoritetsaktieposter4_en.pdf

Dick AR (1993) Strategic trade policy and welfare: the empirical consequences of cross-ownership. J Int Econ 35(3-4):227-249

Dickescheid T (2001) Capital income taxation, cross-ownership, and the structure of public spending. FinanzArchiv Public Finance Anal 57:435-458.

Dietzenbacher E, Temurshoev U (2008) Ownership relations in the presence of cross-shareholding. J Econ 95:189-212

Dixit A (1987) Strategic aspects of trade policy. In: Bewley T (ed) Advances in economic theory: fifth world congress. Cambridge University Press, Cambridge, pp 329-362

Dixit A (1988). Optimal trade and industrial policies for the US automobile industry. In R Feenstra (ed) Empirical methods for international trade. The MIT Press, Cambridge

Eaton J, Grossman GM (1986) Optimal trade and industrial policy under oligopoly. Q J Econ 101:383-406

Fanti L (2013) Cross-ownership and unions in a Cournot duopoly: when profits reduce with horizontal product differentiation. Jpn World Econ 27:34-40

Fanti L (2014) Welfare effects of cross-ownership in a unionised duopoly, Economia e Politica Industriale. J Ind Bus Econ 41(2):21-41

Fanti L (2016) Interlocking cross-ownership in a unionised duopoly: When social welfare benefits from "more collusion." J Econ 119(1):47-63

Fanti L, Buccella D (2016a) Strategic trade policy and union-firm bargaining agenda. J Int Trade Econ Dev 25(6):787-808

Fanti L, Buccella D (2016b) Passive unilateral cross-ownership and strategic trade policy. Econ Open Access Open Assess E J, 10 (2016-10): 1-21.

Farrell J, Shapiro C (1990) Asset ownership and market structure in oligopoly. RAND Journal of Economics 21:275-292

Flath D (1991) When is it rational for firms to acquire silent interests in rivals? Int J Ind Organ 9:573-583

Foros $\varnothing$, Kind HJ, Shaffer G (2011) Mergers and partial ownership. Eur Econ Rev 55(7):916-926

Gilo D, Spiegel Y (2003) Partial cross ownership and tacit collusion. The Center for the Study of Industrial Organization at Northwestern University, Working Paper \#0038.

Goldberg, P. K. (1995). Product differentiation and oligopoly in international markets: the case of the U.S. automobile industry. Econometrica 63(4):891-951.

Gössling S, Fichert F, Forsyth P (2017) Subsidies in aviation. Sustainability 9(8):1295

Grossman GM (1986). Strategic export promotion: a critique, In Krugman P (ed), Strategic trade policy and the new international economics. The MIT Press, Cambridge

Grossman G, Richardson M, David J (1986) Strategic U.S. trade policy: a survey of issues and early analyses. In: Baldwin RE, Richardson JD (eds) international trade and finance, 3rd edn. Little, Brown, Boston, pp 95-113

Hansen RG, Lott JR (1996) Externalities and corporate objectives in a world with diversified shareholder consumers. J Financ Quant Anal 31:43-68

Helpman E, Krugman PR (1989) Trade scture. The MIT Press, Cambridge

Krishna K, Hogan K, Swagel P (1989) The nonoptimality of optimal trade policies: the U.S. automobile industry revisited. In: Krugman P, Smith A (eds) Empirical studies of strategic trade policy. University of Chicago Press, Chicago, pp 1979-1985

Krugman P (ed) (1986) Strategic trade policy and the new international economics. The MIT Press, Cambridge

La Porta R, Lopez-de-Silanes F, Shleifer A (1999) Corporate ownership around the world. J Finance 54:471-517

Leahy D, Neary JP (1997) Public policy towards R\&D in oligopolistic industries. Am Econ Rev 87:642-662 
Lee JW, Yoon SY (2020) Cross-border joint venture airlines in Asia: corporate governance perspective. Eur Bus Organ Law Rev 21:709-729

Macho-Stadler I, Verdier T (1991) Strategic managerial incentives and cross ownership structure: a note. J Econ 53(3):285-297

Nain A, Wang Y (2018) The product market impact of minority stake acquisitions. Manage Sci 64(2):825-844

Neary JP, Leahy D (2000) Strategic trade and industrial policy towards dynamic oligopolies. Econ J 110(463):484-508

Nicolini M, Scarpa C, Valbonesi P (2017) Determinants of state aid to firms: the case of the European automotive industry. Ind Corp Chang 26(3):399-420

Osano H (2011) Intercorporate shareholdings and corporate control in the Japanese firm. J Bank Finance 20(6): 1047-1068

Papadopoulos KG, Petrakis E, Skartados P (2019) Product innovation transfer under passive partial ownership holdings. Econ Lett 177:22-25

Qin CZ, Zhang S, Zhu D (2017) A model of endogenous cross-holdings in oligopoly. Front Econ China 12(3):465-479

Reitman D (1994) Partial ownership arrangements and the potential for collusion. J Ind Econ 42:313-322

Reuters (2008) Bayer to buy Possis Medical in \$361 million deal. February 11, 2008. Available on line at https://www.reuters.com/article/us-bayer-medrad/bayer-to-buy-possis-medical-in-361-million-dealidUKL1128026520080211

Reynolds RJ, Snapp BR (1986) The competitive effects of partial equity interests and joint ventures. Int J Ind Organ 4(2):141-153

Scott RE, Glass E (2016) Trans-Pacific Partnership, currency manipulation, trade and jobs. Briefing Paper \#420, Economic Policy Institute. Available on line at https://www.epi.org/publication/trans-pacificpartnership-currency-manipulation-trade-and-jobs/

Scott RE (2016) U.S.-Korea trade deal resultedin growing trade deficits and more than 95,000 lost U.S. jobs. Working Economics Blog, Economic Policy Institute. 5 May 2016. Available online at https:// www.epi.org/blog/u-s-korea-trade-deal-resulted-in-growing-trade-deficits-and-more-than-95000lost-u-s-jobs/

Singh N, Vives X (1984) Price and quantity competition in a differentiated duopoly. RAND J Econ 15:546-554

Spencer BJ (1986) What should trade policy target? In: Krugman P, ed, Strategic trade policy and the new international economics, The MIT Press, Cambridge

Spencer BJ, Brander J (1983) International R\&D rivalry and industrial strategy. Rev Econ Stud 50:707-722

The Economist (2020) Not boxing clever. A subsidies scrap between Boeing and Airbus comes to an end (maybe). Published on 13 Oct 2020, available on line at https://www.economist.com/business/2020/ 10/13/a-subsidies-scrap-between-boeing-and-airbus-comes-to-an-end-maybe

The Seattle Times 2016 Airbus scoffs, Boeing crows as WTO slams EU for failing to address illegal subsidies. Published on 22 Sep. 2016. Available on line at http://www.seattletimes.com/business/ boeing-aerospace/wto-slams-eu-for-failing-to-remedy-harm-to-boeing-from-illegal-airbussubsidies/

The World Bank (2010) Investing across borders 2010: indicators of foreign direct investment regulation in 87 economies. The World Bank Group, Washington

Tremblay VJ, Tremblay CH, Isariyawongse K (2013) Cournot and bertrand competition when advertising rotates demand: the case of honda and scion. Int J Econ Bus 20(1):125-141

Trivieri F (2007) Does cross-ownership affect competition?: Evidence from the Italian banking industry. J Int Finan Markets Inst Money 17(1):79-101

Wharton Research Data Service (2019). Research note regarding Thomson-Reuters Ownership database issues. Available on-line at https://wrds-www.wharton.upenn.edu/pages/support/research-wrds/ research-guides/research-note-regarding-thomson-reuters-ownership-data-issues/

World Trade Organization (WTO) (2016). Dispute settlement: dispute DS316, European CommunitiesMeasures Affecting Trade in Large Civil Aircraft. Available online at https://www.wto.org/english/ tratop_e/dispu_e/cases_e/ds316_e.htm 
Žigić K (2011) Does "non-committed" government always generate lower social welfare than its "committed" counter-part? Strategic trade policy when consumer surplus matters. J Comp Econ 39(4):533-556

Publisher's Note Springer Nature remains neutral with regard to jurisdictional claims in published maps and institutional affiliations. 